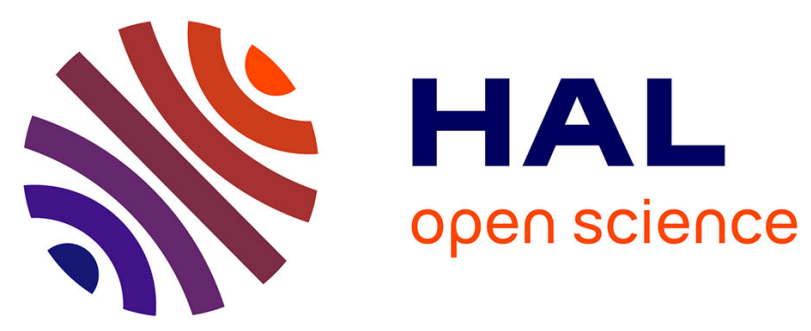

\title{
Topology and Voltage Balance of Series-Connected T-type Inverter for Medium-Voltage Drive Applications
}

Mokhtar Aly, Samir Kouro, Thierry Meynard

\section{To cite this version:}

Mokhtar Aly, Samir Kouro, Thierry Meynard. Topology and Voltage Balance of Series-Connected T-type Inverter for Medium-Voltage Drive Applications. 2020 IEEE 11th International Symposium on Power Electronics for Distributed Generation Systems (PEDG), Sep 2020, Dubrovnik, Croatia. pp.154-158, 10.1109/PEDG48541.2020.9244333 . hal-02999719

\section{HAL Id: hal-02999719 \\ https://hal.science/hal-02999719}

Submitted on 2 Dec 2020

HAL is a multi-disciplinary open access archive for the deposit and dissemination of scientific research documents, whether they are published or not. The documents may come from teaching and research institutions in France or abroad, or from public or private research centers.
L'archive ouverte pluridisciplinaire HAL, est destinée au dépôt et à la diffusion de documents scientifiques de niveau recherche, publiés ou non, émanant des établissements d'enseignement et de recherche français ou étrangers, des laboratoires publics ou privés. 


\title{
Topology and Voltage Balance of Series-Connected T-type Inverter for Medium-Voltage Drive Applications
}

\author{
Mokhtar Aly ${ }^{1.2}$, Samir Kouro ${ }^{2}$, Thierry A. Meynard ${ }^{3}$ \\ 1 \\ Electrical Engineering Department, Aswan University, Aswan 81542, Egypt \\ Electronics Engineering Department, Universidad Tecnica Federico Santa Maria, Valparaiso 2390123, Chile \\ Institut National Polytechnique de Toulouse, University of Toulouse, Toulouse, France
}

\begin{abstract}
The three-level T-type multilevel inverter has proven itself as a promising, highly-efficient, and low-switch-count topology. This paper presents a new topology configuration using series connected T-type multilevel inverters for medium-voltage applications. The proposed topology utilizes the series connection of low power T-type modules to enable medium-voltage operation. The proposed topology is modular, highly efficient, less complex, and with lower component count, compared to other topologies with the same number of levels and voltage operating range. In addition, a simple level-shifted pulse width modulation (LSPWM) method is proposed for achieving voltage balance between the de-link capacitors. The results show the effectiveness of the proposed topology and the proposed LS-PWM method for medium-voltage applications. Moreover, the proposed topology has been compared with the existing medium-voltage converter topologies in the literature.
\end{abstract}

Index Terms-Level shifted pulse width modulation, mediumvoltage drives, multilevel inverter, T-type inverter.

I. INTRODUCTION

The superior performance and wider applicability of multilevel inverters (MLis) have made them favorable over conventional two-level inverters for an increasing number of applications [1], [2]. The improved power quality, reduced common mode voltages, and higher efficiency represent the main benefits of utilizing MLis in medium-voltage applications [3], [4]. The power quality improves with the increase of the number of the output voltage levels. However, increasing the number of levels in the output voltage results in increasing the number of required components. This in turn can impose complexities to other system components such as input transformer design, modulation and controller, capacitor voltage balance, and even increase the system costs [5], [6].

Several MLis topologies have found industrial application in high-power medium-voltage (HP-MV) drive systems, such as cascaded H-bridge (CHB), neutral point clamped (NPC), active NPC (ANPC), flying capacitor (FC), and modular multilevel converters (MMCs), among others [7]-[12]. Moreover, there are several extensions of these basic structures to develop hybrid MLI topologies [5], [13].

The CHB and the MMCs present a modular solutions. However, for medium-voltage applications the circulating current problems, complex control, and sensitivity to passive elements mismatch represent the main drawbacks of MMCs [14], [15]. This has hindered the applicability of MMC for medium-voltage drives applications, and has been only used in practice for high-voltage DC transmission applications. On the other hand, CHB topologies suffer from the high number of required isolated de sources based on complex zig-zag transformers [16], and although they have been successfully used in medium-voltage drives, the lack of a real backto-hack regenerative option (a few manufacturers offer an activefront-end based on two-level three phase voltage source inverters instead of passive diode rectifiers) have restricted their application mainly to pumps, fans and other standard mediumvoltage drives.

NPC based topologies have been presented in the literature with five and seven level output voltages [8], [9], [17]. However, they lack of modularity and require a high number of components due to the necessary clamping diodes, which increase the cost and reduce the efficiency of the system. Capacitor voltage balance also becomes an issue for NPCs with more than three levels when using passive front ends. Improving on the NPCs, several active NPC (ANPC) topologies have been proposed in the literature for mediumvoltage applications [18], [19]. ANPC-based topologies are successful at eliminating the clamping diodes, which improves the efficiency and reduces the cost, and provides a way to distribute thermal losses across devices eliminating the need of power derating [20]. Additionally, hybrid FC and ANPC topologies have been presented in the literature to combine the benefits of FC and the ANPC topologies [4], [20], [21]. Although, they suffer from the high number of power switches and capacitors. In addition, they possess higher conduction losses due to the increased number of conducting switches. In [22], series connection of NPC modules has been proposed for reaching medium-voltage operation. However, this topology inherits the drawbacks of the tradditional NPC, including the clamping diodes.

It has become clear that the existing medium-voltage topologies can suffer from one or more drawbacks, including in- 
TABLE I: Output voltage levels and switching states for the proposed topology $\left(E=V_{d c X} / 4\right)$

\begin{tabular}{cccccccccc}
\hline \multirow{2}{*}{ Amplitude } & \multirow{2}{*}{ Output Voltage } & \multicolumn{4}{c}{ T-type Module 1 } & \multicolumn{5}{c}{ T-type Module 2 } \\
& & $S_{X 11}$ & $S_{X 12}$ & $S_{X 13}$ & $S_{X 14}$ & $S_{X 21}$ & $S_{X 22}$ & $S_{X 23}$ & $S_{X 24}$ \\
\hline $4 V_{d c}$ & $V_{C X 1}+V_{C X 2}+V_{C X 3}+V_{C X 4}$ & 1 & 1 & 0 & 0 & 0 & 0 & 1 & 1 \\
\hline \multirow{2}{*}{$3 V_{d c}$} & $V_{C X 1}+V_{C X 2}+V_{C X 3}$ & 1 & 1 & 0 & 0 & 0 & 1 & 1 & 0 \\
& $V_{C X 2}+V_{C X 3}+V_{C X 4}$ & 0 & 1 & 1 & 0 & 0 & 0 & 1 & 1 \\
\hline \multirow{2}{*}{$2 V_{d c}$} & $V_{C X 1}+V_{C X 2}$ & 1 & 1 & 0 & 0 & 1 & 1 & 0 & 0 \\
& $V_{C X 2}+V_{C X 3}$ & 0 & 1 & 1 & 0 & 0 & 1 & 1 & 0 \\
& $V_{C X 3}+V_{C X 4}$ & 0 & 0 & 1 & 1 & 0 & 0 & 1 & 1 \\
\hline \multirow{2}{*}{$V_{d c}$} & $V_{C X 2}$ & 0 & 1 & 1 & 0 & 1 & 1 & 0 & 0 \\
\hline 0 & $V_{C X 3}$ & 0 & 0 & 1 & 1 & 0 & 1 & 1 & 0 \\
\hline 0 & 0 & 0 & 0 & 1 & 1 & 1 & 1 & 0 & 0 \\
\hline
\end{tabular}

creased switch count, increased number of isolated dc sources, low efficiency, lack of modularity, complex modulation or control and/or increased number of sensors. In this paper a new series-connected T-type topology for medium-voltage drive applications is presented. The proposed topology benefits the advantages of three-level T-type modules of lower conduction losses, and lower number of components. In addition, the series connection of low voltage T-type modules are employed for fulfilling the medium-voltage drive operation. In addition, a simple method for voltage balance over the dc-link capacitors is proposed in this paper. The proposed controller is based on the level-shifted pulse width modulation (LS-PWM) and the redundancy property of T-type inverters. Thence, dclink voltage control and balance can be achieved through employing simple control without adding more components nor complexity to the drive control system.

The remaining of the paper is organized as follows: Section II presents the power circuit topology and the operation of the new proposed topology. The proposed LS-PWM method for capacitor voltage balance control is presented in Section III. The simulation results of the proposed topology and controller are provided in Section IV. The proposed topology is compared with the existing topologies in the literature in Section V. Finally, conclusions are addressed in Section VI.

\section{Circuit TOPOlOgY AND OPERATION}

The three level T-type inverter has proven superior performance for different applications, including renewable energy applications, UPS systems and motor drive applications [23], [24]. The T-type inverter is advantageous from the number of component and reduced conduction losses point of views. Each inverter leg is composed of four power switches, wherein two of them are similar to the conventional H-bridge leg and the other two are connected in bidirectional cell to the neutral point of the inverter. However, the traditional three-level Ttype modules are not suitable for several medium-voltage applications due to the limitations of the blocking voltages of existing commercial switches.

Fig. 1 shows the circuit configuration of the proposed fivelevel topology. Each phase leg is constructed though the series connection of two three-level T-type modules. An isolated dc-source is required for each phase leg, which in normally

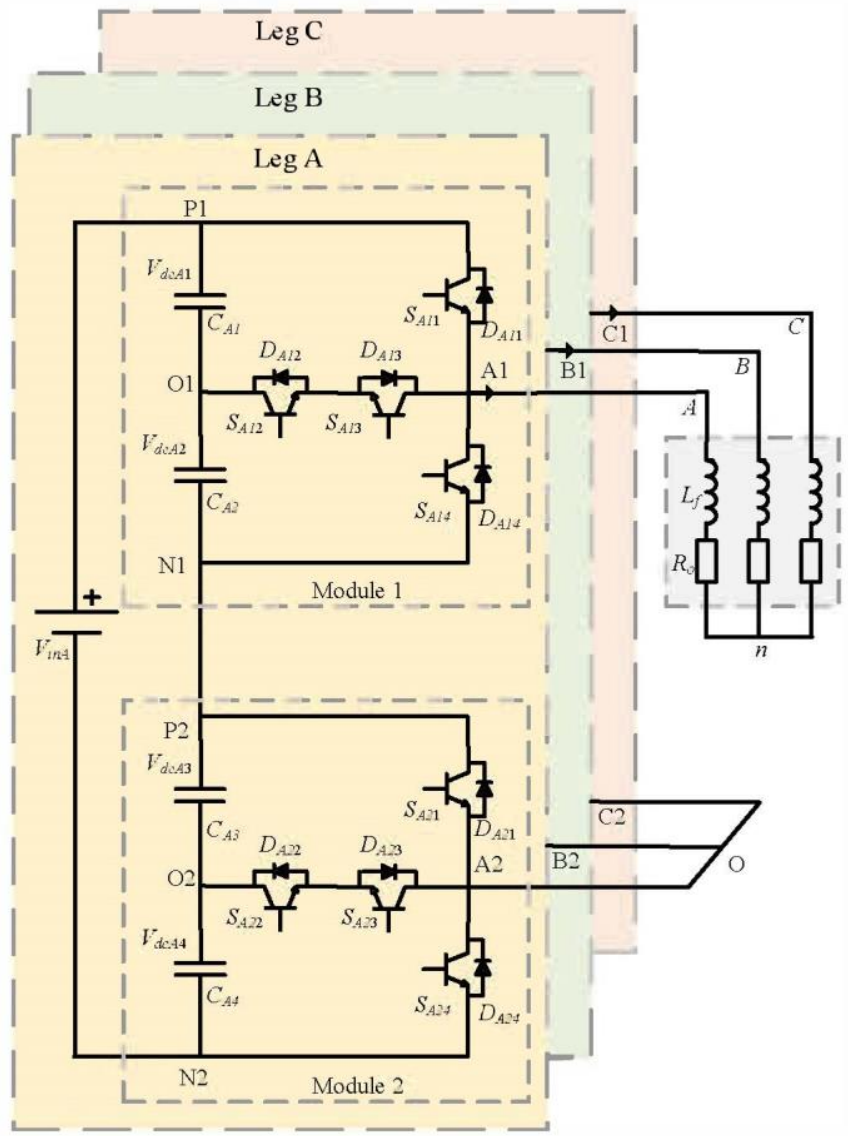

Fig. 1: Power Circuit of the proposed series connected T-type topology.

generated by phase shifted transformers followed by diode bridge rectifiers. The dc voltage is divided equally among the four dc-link capacitors $\left(C_{X 1}, C_{X 2}, C_{X 3}, C_{X 4}\right)$, (where $X \in$ $A, B$, or $C)$. Hence, each capacitor voltage $\left(V_{d c X 1}, V_{d c X 2}\right.$, $\left.V_{d c X 33}, V_{d c X 4}\right)$ is controlled to hold one fourth of the dclink voltage $\left(V_{d c X} / 4\right)$. The three phase output of the inverter are connected to the load $\left(L_{X}\right.$ inductance in series with $R_{X}$ resistance). The inverter has the neutral point of the load output $n$, and the connection of the lower module forms a floating neutral point $N$. Table I summarizes the output voltage levels of each phase leg and switch combination of the proposed topology. 
Each T-type module can generate three level output voltage, whereas the connection of two series T-type modules can generate five level output voltage. It can be seen from Table I that each phase leg has nine different switching states, and some of the states are redundant. Redundant switching states can generate the same output voltage level, while they employ different dc-link capacitors and different power switches. Moreover, the charging and/or discharging of dclink capacitors is highly dependent on the employed switching state.

\section{Voltage B ALANCE METHOD}

Several methods have been proposed in the literature for controlling the dc link capacitor voltage unbalance, such as space vector PWM (SVPWM) [23], [25], phase shift PWM (PS-PWM), level-shifted PWM (LS-PWM) [26], model predictive control (MPC) [27], to name a few. In [28], the PSPWM has been proposed for controlling capacitor voltages of the series NPC converters. However, complexity arises for the PS-PWM at determining the output voltage level for the phase output instead of the module output. Whereas, the LSPWM can determine the output level directly and then the redundant switching states can be employed for controlling the capacitor voltages. Therefore, the LS-PWM method is selected for implementing the proposed voltage balance algorithm in this paper.

Fig. 2 shows the flowchart of the proposed voltage balance algorithm. The proposed controller is based on the LS-PWM through employing the redundancy property of the proposed topology. Firstly, the proposed algorithm generates the modulating signal and the four carrier waveforms for each phase leg. Secondly, through the comparison of the modulating signal and the carrier, the algorithm defines the operating region of the required output voltage levels. Thirdly, the algorithm checks the redundancy in the required voltage levels as shown in Table I. For instance, each of the voltage levels $3 V_{d c}$, and $V_{d c}$ possesses two redundant switching states, and the voltage level $2 V_{d c}$ has three redundant switching states. Whereas, the voltage levels $4 V_{d c}$, and zero do not have redundant switching states. Lastly, suitable redundant vector is selected according to its effects on the voltages of dc-link capacitors and then the gating signals are generated to drive the inverter. For example, the two redundant vectors of the voltage level $3 V_{d c}$ at positive current direction have the possibility of charging the capacitor $C_{X 1}$ or $C_{X 4}$ according to their relative charge. Thence, the suitable redundant vector is selected for this level to achieve the voltage balance over the capacitors.

\section{Simulation Results}

The proposed topology and voltage balance algorithm are simulated using the PLECS software. The main parameters of the selected case study are: input dc voltage $10.7 \mathrm{kV}$, output line-line voltage $6.9 \mathrm{kV}$, dc-link capacitors $2.2 \mathrm{mF}$, output full load resistance $25 \Omega$, and output inductance $3 \mathrm{mH}$. The proposed inverter and voltage balance algorithm are tested at different load changes and modulation index $((\mathrm{mi})$ changes).

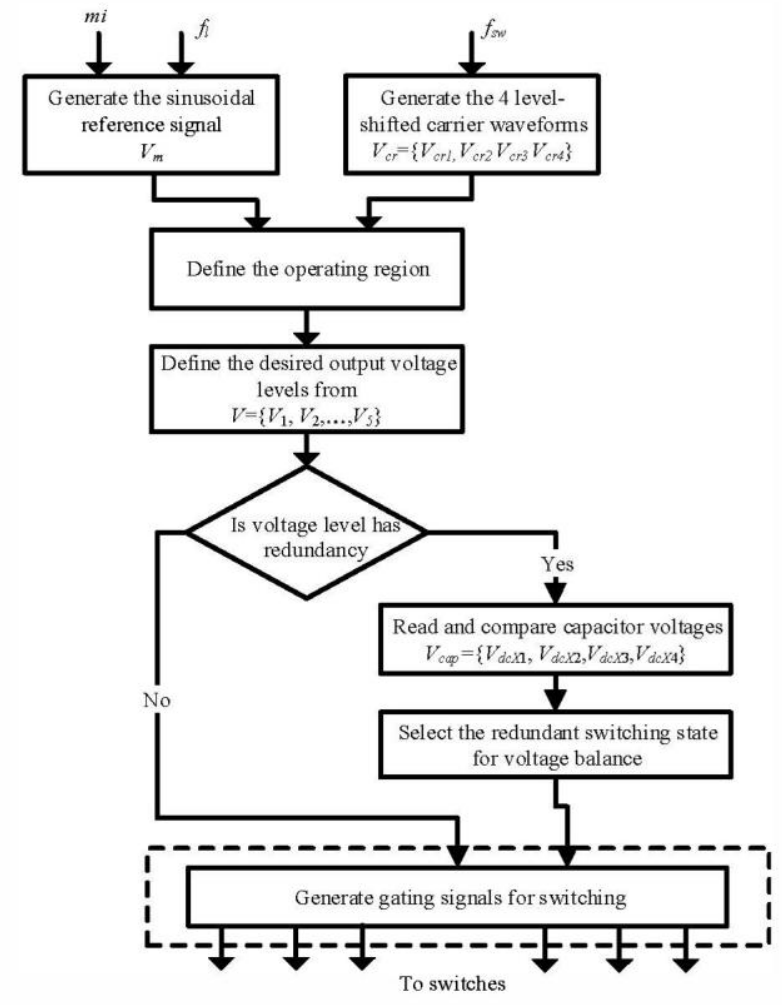

Fig. 2: Flowchart of the proposed voltage balance algorithm.

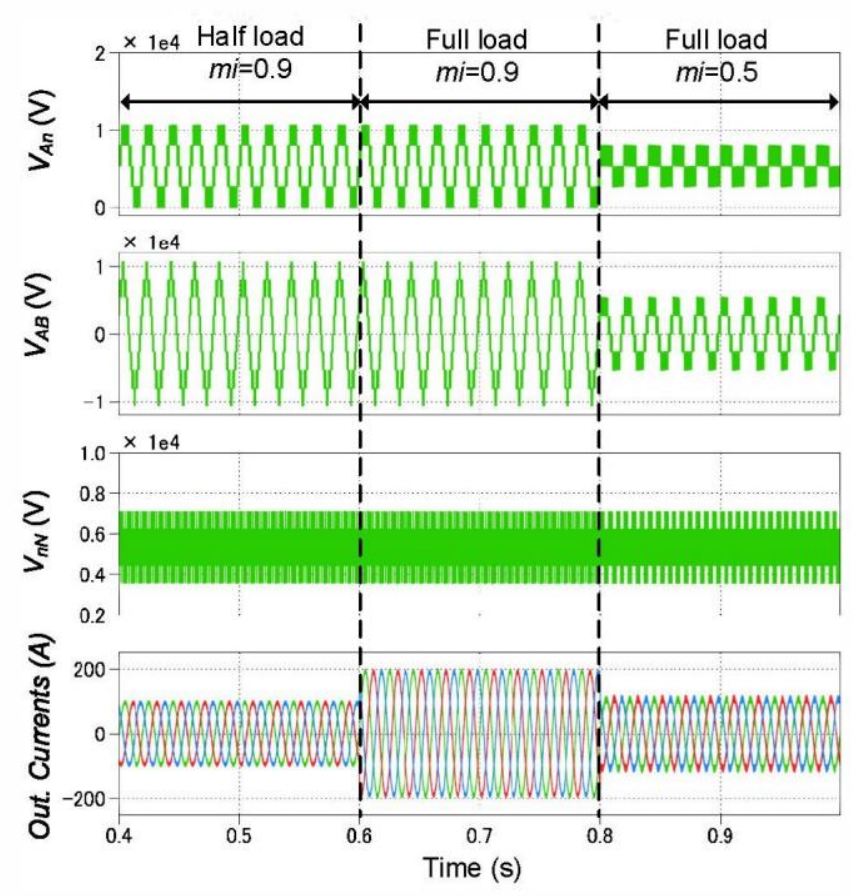

Fig. 3: Simulation results of the proposed topology.

Fig. 3 shows the output phase voltage $V_{A n}$, line-line voltage $V_{A B}$, the voltage between the neutral points $V_{n N}$, and the output currents of the inverter. It can be seen that at $m i$ of 0.9 generates five output levels, and nine levels in the line- 
TABLE II: Component comparison of the new proposed topology $\left(E=V_{i n}\right)$.

\begin{tabular}{|c|c|c|c|c|c|c|c|}
\hline & iterion & $\mathrm{CHB}$ & Series NPC & H-T-type & MMC & & $\begin{array}{l}\text { Proposed } \\
\text { topology }\end{array}$ \\
\hline \multirow{3}{*}{ Sources } & Isolated dc sources & 6 & 3 & 1 & 1 & & 3 \\
\hline & dc-link capacitors & 0 & 12 & 2 & 0 & & 12 \\
\hline & Flying capacitors & 0 & 0 & 0 & 24 & & 0 \\
\hline \multirow{3}{*}{ Switches } & Count & 24 & 24 & 24 & 48 & & 24 \\
\hline & Blocking voltages & $24 \times\left(V_{i n} / 2\right)$ & $24 \times\left(V_{i n} / 4\right)$ & $\begin{array}{l}12 \times\left(V_{i n}\right)+12 \times \\
\left(V_{i n} / 2\right)\end{array}$ & $\begin{array}{l}48 \\
\left(V_{i n} / 4\right)\end{array}$ & $x$ & $\begin{array}{l}12 \times(\operatorname{Vin} / 2)+ \\
12 \times(\operatorname{Vin} / 4)\end{array}$ \\
\hline & $\begin{array}{l}\text { Normalized } \\
\text { blocking voltage }\end{array}$ & $12 E$ & $6 E$ & $18 E$ & $24 E$ & & $9 E$ \\
\hline \multirow{3}{*}{ Diodes } & Count & 0 & 12 & 0 & 0 & & 0 \\
\hline & Blocking voltages & - & $12 \times\left(V_{i n} / 4\right)$ & $\begin{array}{ll}- & \\
\end{array}$ & - & & - \\
\hline & $\begin{array}{l}\text { Normalized total } \\
\text { blocking voltage }\end{array}$ & - & $3 E$ & - & - & & - \\
\hline \multirow{3}{*}{ Total components } & Count & 24 & 36 & 24 & 48 & & 24 \\
\hline & Blocking voltages & $24 \times\left(V_{i n} / 2\right)$ & $36 \times\left(V_{i n} / 4\right)$ & $\begin{array}{l}12 \times\left(V_{i n}\right)+12 \times \\
\left(V_{i n} / 2\right)\end{array}$ & $\begin{array}{l}48 \\
\left(V_{i n} / 4\right)\end{array}$ & $x$ & $\begin{array}{l}12 \times(\operatorname{Vin} / 2)+ \\
12 \times(\operatorname{Vin} / 4)\end{array}$ \\
\hline & $\begin{array}{l}\text { Normalized total } \\
\text { blocking voltage }\end{array}$ & $12 E$ & $9 E$ & $18 E$ & $24 E$ & & $9 E$ \\
\hline
\end{tabular}

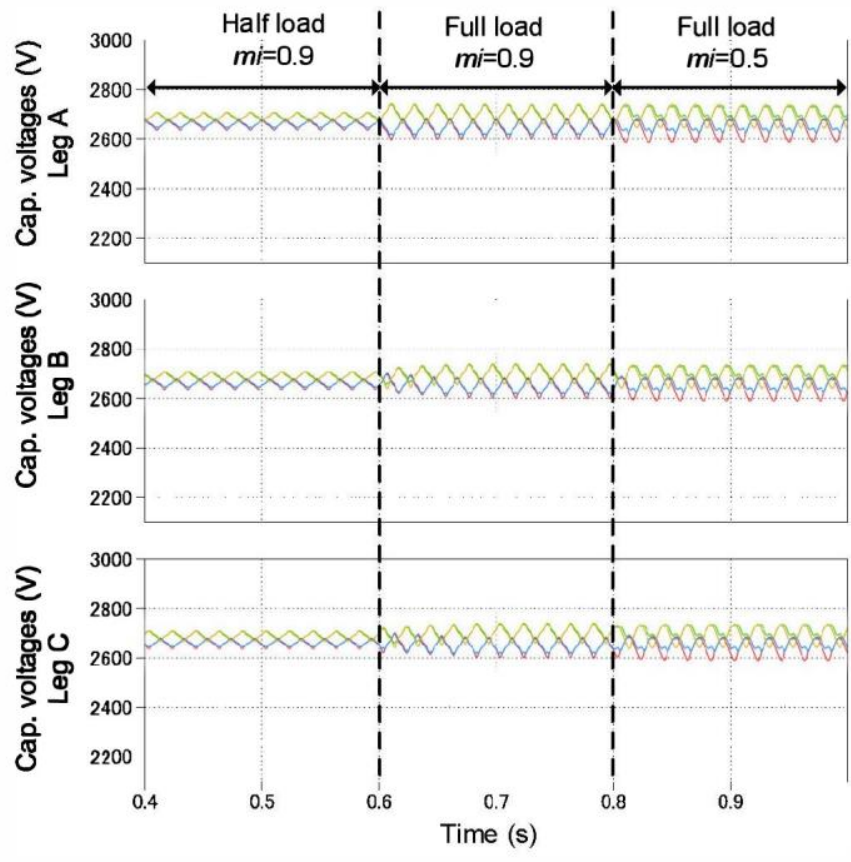

Fig. 4: Simulation results for the dc-link capacitors voltages of the three legs.

line voltage. Whereas at $m i=0.5$, the phase voltages have a three-level output, and the line-line voltages a five-level output. Moreover, the proposed method can generate a fixed switching frequency output voltage.

Fig. 4 shows the voltages over the dc-link capacitors of the three-phase legs. It can be seen that the proposed algorithm can preserve balanced voltages over the dc-link capacitors at various load changes and $m i$ changes. Firstly, the controller is tested at step change of the load impedance, which has proved fast balance of the voltages without fluctuations. Secondly, the system is tested at step change of the modulation index $m i$. It can be seen that the voltages are still balanced without drifting. However, as expected the ripples in the dc-link capacitor voltages are dependent on the loading and $m i$ operating condition. The proposed LS-PWM is advantageous at achieving voltage control of capacitor voltages at each phase independently.

\section{TOPOLOGY COMPARISON}

Table II compares the proposed topology with the most prevalent medium-voltage topologies in the literature. The performance criteria includes the sources count and capacitors, main switches, diodes, and their voltage stresses. It can be seen that the proposed topology requires lower number of isolated dc sources than the CHB topology. In addition, the proposed topology possesses lower number of switches than MMC topology. The proposed topology and the series connected NPC topology require lower total blocking voltages than alternative topologies. Moreover, the proposed topology does not need clamping diodes as in the series connected NPC topology. The proposed topology can be implemented using the commercially available T-type modules. Thence, the proposed topology eliminates the need for flying capacitors and clamping diodes. This in turn verifies the reduction of the required number of components compared to the other existing topologies in the literature.

\section{CONCLUSIONS}

A new series connected T-type topology and simple voltage balance algorithm are presented in this paper for mediumvoltage applications. The new proposed topology benefits lower component count, voltage stresses, and without using flying capacitors. In addition, the proposed voltage balance algorithm is based on using the LS-PWM and the redundancy property between switching state, and so it represents simple solution without need for complex calculations. The results of the proposed topology and controller have been shown in the paper at different operating points. The operation, 
performance comparison of the proposed topology, and the proposed controller have been presented in the paper. The superior performance of the proposed topology and de-link capacitor voltage controller has become clear.

$\begin{array}{cccccc}\text { This work was } & \text { supported by } & \text { SERC } & \text { Chile } \\ \text { (ANID/FONDAP15110019) } & \text { and } & \text { by } & \text { AC3E }\end{array}$

(ANID/Basal/FB0008).

[1] M. Aly and H. A. Ramadan, "Design and implementation of adaptive SVPWM algorithm for multilevel inverters in renewable energy applications," Solar Energy, vol. 183,p p. 745-754,M ay 2019.

[2] E. M. Ahmed, M. Aly, A. Elmelegi, A. G. Albarbi, and Z. M. Ali,

PV systems in distribution network with unbalanced loads," Energies, vol. 12, no. 24,p . 4799,D ec. 2019.

"Multifunctional distributed MPPT controller for 3p4w grid-connected

[3] T. Abhilash, K. Annamalai, and S. V. Tinmtala, "A seven-level vsi with a front-end cascaded threle- evel inverter and flying-capacitor-fed h-bridge:' IEEE Transactions on Industry Applications, vol. 55, n o. 6, pp. 6073-6088,2 019 .

[4] A. K. Yadav, K. Gopakumar, K.R . R, L. Umanand,S . Bhattacharya, and W. Jarzyna, "A hybrid 7-level inverter nsing low-voltage devices and operation with single de-link," IEEE Transactions on Power Electronics, vol. 34, no. 10, pp. 9844-9853,2 019.

[5] Q. A. Le and D. Lee, "A novel six-level inverter topology for mediumvoltage applications," IEEE Transactions on Industrial Electronics, vol. 63,n o. 11,p p. 7195-7203,2 016.

[6] S.M. Said,M . Aly, B. Hartman,n A. G. Albarbi, and E.M . Ahmed, "Smes-based fuzzy logic approach for enhancing the reliability of microgrids equipped with pv generators," IEEE Access, vol. 7, pp. 92 059-92069,2 019

[7] S. K. Sahoo and T. Bhattacharya, "Phase-shifted carrier-based synchronized sinusoidal pwm techniques for a cascaded h-bridge multilevel inverter:' IEEE Transactions on Power Electronics, vol. 33,n o. $1, \mathrm{pp} .513-524,2018$.

[8] D. Cui and Q. Ge, "A novel hybrid voltage halance method for five-level diode-clamped converters:' IEEE Transactions on Industrial Electronics, vol. 65,n o. 8,pp . 6020-6031,2 018.

[9] H. A. Hotait,A . M.M assoud, S. J. Finney,an d B. W. Williams," Capacitor voltage balancing using redundant states of space vector modulation for live-level diode clamped inverters," JET Power Electronics, vol. 3, no. 2,p p. 292-313,2 010

[10] G. Tan, Q. Deng, and Z. Liu, "An optimized svpwm strategy for five-level active npc (51-anpc) converter;' IEEE Transactions on Pawer Electronics, vol. 29,n o. 1,p p. 386-395, 2014.

[11] A. M. Y. M. Ghias, J.P ou, V. G. Agelidis,a nd M. Ciobotaru," Optimal switcbing transition-based voltage balancing method for flying capacitor multilevel converters," IEEE Transactions on Power Electronics, vol.3 0, no. 4, pp. 1804-1817,2 015

[12] A. M. Y. M. Gbias, J. Pou, and V. G. Agelidis, "Voltage-balancing method for stacked multicell converters using phase-disposition pwm," IEEE Transactions on Industrial Electronics, vol. 62,n o. 7,p p. 40014010,2015 .

[16] M. Malinowski, K. Gopakumar, J. Rodriguez,a nd M.A . Perez," A survey on cascaded multilevel inverters," IEEE Transactions on Industrial Electronics, vol. 57, no. 7,pp . $2197-2206,2$ 010.

[13] J. Ebrabimi and H. Karshenas," A new single de source six-level flying capacitor based converter with wide operating range," IEEE Transactions on Power Electronics, vol. 34,n o. 3,p p. $2149-2158,2019$.

[14] R. Lizana,M . A. Perez, S. Bernet, J.R . Espinoza, and J. Rodriguez, "Control of arm capacitor voltages in modular multilevel converters; IEEE Transactions on Power Electronics, vol. 31,n o. 2,p p. 1774-1784, 2016.

[15] H. Liu,K . Ma, Z. Qin, P. C. Loh,a nd F. Blaabjerg, "Lifetime estimation of mmc for offshore wind power hvdc application: IEEE Journal of Emerging and Selected Topics in Power Electronics, vol. 4,n o. 2,pp. 504-511,2 016 .

[17] H. Wang, L. Kou, Y. Liu, and P. C. Sen, "A seven-switch fivelevel active-neutral-point-clamped converter and its optimal modulation strategy; IEEE Transactions on Power Electronics, vol. 32, no. 7, pp. 5146-5161, 2017.

[18] D. Andler, R. Alvarez, S. Bernet, and J. Rodriguez, "Switcbing loss analysis of 4.5-kv-5.5-ka igcts within a 31-anpc phase leg prototype," IEEE Transactions on Industry Applications, vol. 50,n o. 1,p p. 584$592,2014$.

[19] J.L i, A. Q.H uang, Z. Liang,a nd S.B hattacharya, "Analysis and design of active npc (anpc) inverters for fault-tolerant operation of bigh-power electrical drives; - IEEE Transactions on Pawer Electronics, vol. 27, no. 2, pp. 519-533,2 012 .

[20] Z. Wang,C . Gao,C. Chen, J.X iong, and K. Zhang, "Ripepl analysis and capacitor voltage balancing of live-level hybrid clamped inverter (51he) for medium-voltage applications," IEEE Access, vol. 7,p p. 8607786089,2019

[21] S. Xu, J. Zhang, and X. Hu, "Model predictive control for a hybrid multilevel converter with different voltage ratios," IEEE Journal of Emerging and Selected Topics in Power Electronics, vol. 7, no. 2, pp. 922-935, 2019.

[22] A. Dekka, B. Wu, and M. Narimani, "A series-connected multilevel converter: Topology, modeling, and control;' IEEE Transactions on Industrial Electronics, vo1. 66, no. 8,p p. 5850-5861,2 019.

[23] M. Aly, E.M . Ahmed, and M. Shoyama, "Developing new lifetime prolongation SVM algorithm for multilevel inverters with thermally aged power devices: JET Power Electronics, vol. 10,n o. 15,p p. 2248-2256, Dec. 2017.

[24] M. Aly and M. Shoyama, "An efficient nentral point voltage control algorithm with reduced switching losses for three level inverters," in 20/4 IEEE International Conference on Power and Energy (PECon), 2014,pp. 330-335.

[25] M. Aly, G. M. Donsoky, and M. Shoyama, "An overheating-tolerant space vector modulation algorithm for multilevel inverters," IEEJ Transactions on Electrical and Electronic Engineering, vol.1 1, pp. S75-S83, Dec. 2016.

[26] M. Aly,E . M. Ahmed,S . Kouro,a nd M. Shoyama," Capacitor voltage ripple reduction modulation method for string photovoltaic inverters," in 201921 st International Middle East Pawer Systems Conference (MEPCON), 2019, pp. 852-857.

[27] A. Bahrami,M . Narimani,M . Norarnbuena,an d J. Rodrignez, "Current control of a seven-level voltage source inverter:' IEEE Transactions on Power Electronics, vol.3 5, no.3, pp. 2308-2316,2 020.

[28] A. Dekka, R. L. Fuentes, M. Narimani, and B. Wu, "Voltage balancing of a modular neutral-point-clamped converter with a carrier-based modulation scheme:' IEEE Transactions on Power Electronics, vol. 33, no. 10,p p. 8208-8212, 2018. 